\title{
Neurology in Gloucestershire: the clinical workload of an English neurologist
}

\author{
DAVID L STEVENS
}

From the Gloucestershire Royal Hospital, Gloucester, UK

SUMMARY Attempts to determine the ideal number of consultant neurologists that will be required in the United Kingdom in the future are hampered by a lack of information on a variety of topics, one of which concerns the workload of the average neurologist at the present time. This paper attempts to correct this deficiency by examining the clinical workload of a single handed neurologist practising in the south west of England. Diagnostic information is given on the 3020 new patients seen during 1984-1986 and is compared with similar data on 836 new patients seen in 1975. The pattern of diagnoses on these patients varies little from year to year, indicating a constancy of referral habit of those who seek neurological advice. However, the referral rates for different conditions do not correspond with what would be expected from epidemiological data, for when the incidence of particular conditions in the neurology clinic is compared with the calculated incidence in the community, very wide variations are noted. The implications of these data are discussed and it is suggested that further studies should be performed before detailed predictions are made on how many neurologists will be needed in this country in the future.

Even though the speciality of clinical neurology has grown in the United Kingdom in the last few decades, there are still too few consultant neurologists in this country..$^{1-3}$ In order to establish how many we need it is necessary to study a number of variables. Hitherto, detailed analyses of the nation's need have not been done because there has been a lack of information in some of the relevant areas.

A starting point is to estimate how much neurological disease is present in the community. This is a matter that has been studied extensively by Kurtzke, ${ }^{4}$ who has published tables of data on incidence, prevalance and duration of illness for a wide variety of neurological diseases. His analysis was intended to illuminate the situation in the United States, but many of his references are to the European literature, so it is likely that his figures apply reasonably well to the United Kingdom. No comparable British study is available, although one study of the incidence and prevalence of neurological disease in a small community has been published. ${ }^{5}$ The American study, even though it has defects, is the most comprehensive attempt at measuring the size of the burden of neurological disease in the population.

Having established the size of the problem, it is

Address for reprint requests: Dr D L Stevens, Department of Neurology, Gloucester Royal Hospital, Gloucester GL1 3NN, UK.

Received 20 May 1988.

Accepted 8 November 1988 necessary next to estimate the proportion of those patients with neurological disorders who need to see a neurologist. Kurtzke has addressed this question too, although it is clear that his estimates reflect the system of medical care and the expectations of patients in the United States, with the consequence that some of his conclusions do not translate comfortably to the situation that currently exists in the United Kingdom.

Finally, as a measure of how well neurologists are doing at picking up the problems that could legitimately be theirs, the actual workload of neurologists requires evaluation. Some studies exist on what is done in the United States, ${ }^{6-11}$ but little has been published by neurologists working in this country. Indeed, in the United Kingdom publications which analyse what neurologists actually do ${ }^{12}$ are outnumbered by those which suggest what they could or should do. ${ }^{13-15}$

The purpose of this paper is to illustrate certain clinically related aspects of the workload of a single handed neurologist, in the hope that the data will permit future discussions on the topic of neurological services and manpower to be based more surely upon the statistical realities of what is actually done and less upon the theoretical predictions of what should be done.

\section{Neurological service in Gloucestershire}

Since 1973 the author has been the only consultant neurologist in Gloucestershire (population 512,200 ), a predominantly rural county in south west England, measuring 35 miles north-south and 45 miles east-west. The two main towns of 
Gloucester (population 90,900) and Cheltenham $(86,600)$ are eight miles apart and more or less in the centre of the county. The area is divided into two Health Districts. The neurological service is based at the Gloucestershire Royal Hospital in Gloucester, but additional out-patient clinics are held at the Cheltenham General Hospital. Supporting medical staff are few in number and junior in rank. In 1973 there were two Senior House Officers but now neurology has 9/10ths of the time of a Senior House Officer and 5/10ths of a pre-registration House Physician. There is a General Practitioner Clinical Assistant with training in neurology, who helps with one out-patient session a week and another who supervises the day to day care of the residents in the Young Disabled Unit, of which the author is the consultant in charge. There is no consultant clinical neurophysiologist, so the author reports on electroencephalographs and evoked response studies and he performs all electromyographic and nerve conduction studies.

Diagnostic facilities in the area are good, there being computed tomography (CT) scanners in Gloucester (installed 1977) and Cheltenham (installed 1983) and adequate equipment for neurophysiology. The local hospitals have extensive radiological and laboratory facilities, although the neuropathology service is provided from Bristol. Adjacent neurological departments are situated at Bristol (35 miles south), Cardiff (50 miles south west), Birmingham (40 miles north) and Oxford (40 miles east). The nearest neurosurgical unit is at Bristol.

\section{Data collection}

From the start of the service in 1973, statistical data have been collected on all new out-patients, emergency admissions, patients seen for opinions on other wards, domiciliary visits, medicolegal patients and private patients. A record is kept of the patient's name, address, date of birth, hospital number (if applicable), family doctor and referring consultant or other agency (if applicable). Up to four diagnoses are recorded, the first of which is neurological and the others are for additional significant neurological conditions or for
Table 1 New patients and numbers of diagnoses per year

\begin{tabular}{|c|c|c|c|c|c|}
\hline & 1975 & 1984 & 1985 & 1986 & $\begin{array}{l}\text { 1984-86 } \\
\text { Total }\end{array}$ \\
\hline $\begin{array}{l}\text { New patients } \\
\text { Diagnoses } \\
\text { Diagnoses per patient }\end{array}$ & $\begin{array}{l}836 \\
967 \\
1 \cdot 16\end{array}$ & $\begin{array}{c}936 \\
1144 \\
1.22\end{array}$ & $\begin{array}{l}1018 \\
1282 \\
2^{1.26}\end{array}$ & $\begin{array}{l}1066 \\
1288 \\
6^{1 \cdot 21}\end{array}$ & $\begin{array}{l}3020 \\
3714 \\
1 \quad 1 \cdot 23\end{array}$ \\
\hline
\end{tabular}

relevant non-neurological disorders. From 1973 to 1983 these data were stored on file cards, but since 1983 they have been kept in coded form in a computerised diagnostic index which is part of the Gloucestershire Royal Hospital patient administration system.

\section{Diagnostic data}

General statistics. The majority of the diagnostic data to be presented relates to the years 1984 to 1986 , but additional data for 1975 (ten years prior to the middle year of the main study) are used for comparison purposes. During the three years 1984-1986 a total of 3020 new patients were seen, on whom 3714 diagnoses were made. Table 1 outlines the annual figures and illustrates the consistency of allocation of multiple diagnoses.

Diagnostic categories. Details are given in Table 2 of the general headings under which the diagnoses are grouped. The system used for coding diagnoses is personal and is not based on the International Classification of Disease, for that system is difficult to use in a clinical setting and is relatively insensitive to the subtle distinctions that may be required by a clinician. The broad diagnostic headings are uncomplicated and this facilitates day to day coding of patients. The majority of the headings in the table are self explanatory, but two categories require explanation. "Disorders of Function" covers a range of speech disorders, motor and sensory problems and others where there is no clear cut detectable cause or where an alternative label would be inappropriate.

Table 2 Broad diagnostic categories

\begin{tabular}{|c|c|c|c|c|c|c|c|c|c|c|}
\hline \multirow[b]{2}{*}{ Category } & \multicolumn{2}{|c|}{1975} & \multicolumn{2}{|l|}{1984} & \multicolumn{2}{|l|}{1985} & \multicolumn{2}{|l|}{1986} & \multicolumn{2}{|c|}{$1984-86$} \\
\hline & $N$ & $\%$ & $N$ & $\%$ & $N$ & $\%$ & $N$ & $\%$ & $N$ & $\%$ \\
\hline $\begin{array}{l}\text { Disorders of consciousness } \\
\text { Pain in the head or face } \\
\text { Involuntary movement disorders } \\
\text { Cranial nerve disorders } \\
\text { Peripheral nerve/root disorders } \\
\text { Vascular disease nervous system } \\
\text { Spine and spinal cord disease } \\
\text { Disorders of function } \\
\text { Trauma to head or face } \\
\text { Multiple Sclerosis } \\
\text { Pain not in head or face } \\
\text { Infections of the nervous system } \\
\text { Tumours of nervous system } \\
\text { Muscle disease } \\
\text { Diffuse nervous system disease } \\
\text { Trauma not to head or face }\end{array}$ & $\begin{array}{r}165 \\
140 \\
67 \\
40 \\
72 \\
80 \\
64 \\
46 \\
44 \\
52 \\
12 \\
10 \\
38 \\
18 \\
11 \\
1\end{array}$ & $\begin{array}{r}17 \cdot 1 \\
14 \cdot 5 \\
6 \cdot 9 \\
4 \cdot 1 \\
7 \cdot 4 \\
8 \cdot 3 \\
6 \cdot 6 \\
4 \cdot 8 \\
4 \cdot 6 \\
5 \cdot 4 \\
1 \cdot 2 \\
1 \cdot 0 \\
3 \cdot 9 \\
1 \cdot 9 \\
1 \cdot 1 \\
0 \cdot 1\end{array}$ & $\begin{array}{r}181 \\
183 \\
73 \\
87 \\
68 \\
70 \\
87 \\
62 \\
48 \\
42 \\
18 \\
26 \\
17 \\
26 \\
16 \\
12\end{array}$ & $\begin{array}{r}15 \cdot 8 \\
16 \cdot 0 \\
6 \cdot 4 \\
7 \cdot 6 \\
5 \cdot 9 \\
6 \cdot 1 \\
7 \cdot 6 \\
5 \cdot 4 \\
4 \cdot 2 \\
3 \cdot 7 \\
1 \cdot 6 \\
2 \cdot 3 \\
1 \cdot 5 \\
2 \cdot 3 \\
1 \cdot 4 \\
1 \cdot 0\end{array}$ & $\begin{array}{r}218 \\
209 \\
86 \\
83 \\
74 \\
90 \\
74 \\
60 \\
55 \\
56 \\
36 \\
31 \\
27 \\
27 \\
15 \\
14\end{array}$ & $\begin{array}{r}17.0 \\
16.3 \\
6.7 \\
6.5 \\
5.8 \\
7.0 \\
5.8 \\
4.7 \\
4.3 \\
4.4 \\
2.8 \\
2.4 \\
2.1 \\
2.1 \\
1.2 \\
1.1\end{array}$ & $\begin{array}{r}244 \\
185 \\
104 \\
93 \\
107 \\
81 \\
72 \\
59 \\
44 \\
47 \\
30 \\
25 \\
26 \\
15 \\
20 \\
11\end{array}$ & $\begin{array}{r}18.9 \\
14.4 \\
8.1 \\
7.2 \\
8.3 \\
6.3 \\
5.6 \\
4.6 \\
3.4 \\
3.6 \\
2.3 \\
1.9 \\
2.0 \\
1.2 \\
1.6 \\
0.9\end{array}$ & $\begin{array}{r}643 \\
577 \\
263 \\
263 \\
249 \\
241 \\
233 \\
181 \\
147 \\
145 \\
84 \\
82 \\
70 \\
68 \\
51 \\
37\end{array}$ & $\begin{array}{r}17.3 \\
15.5 \\
7.1 \\
7.1 \\
6.7 \\
6.5 \\
6.3 \\
4.9 \\
4.0 \\
3.9 \\
2.3 \\
2.2 \\
1.9 \\
1.8 \\
1.4 \\
1.0\end{array}$ \\
\hline Non-neurological disease & 107 & $11 \cdot 1$ & 128 & $11 \cdot 1$ & 127 & 9.9 & 125 & $9 \cdot 7$ & 380 & $10 \cdot 2$ \\
\hline Total number of diagnoses & 967 & $100 \cdot 0$ & 1144 & 99.9 & 1282 & $100 \cdot 1$ & 1288 & $100 \cdot 0$ & 3714 & $100 \cdot 1$ \\
\hline
\end{tabular}


Table 3 Conditions diagnosed on average once or more each month

\begin{tabular}{rlr}
\hline Rank & Diagnosis & $1984-86$ \\
\hline 1 & Epilepsy late onset (all types) & 248 \\
2 & Migraine (all types) & 241 \\
3 & Epilepsy early onset (all types) & 224 \\
4 & Tension headache (all types) & 222 \\
5 & Head and facial injuries (all categories) & 147 \\
6 & Multiple Sclerosis & 140 \\
7 & Cerebral and brain stem stroke & 124 \\
8 & ?Fit/?Faint & 102 \\
9 & Parkinson's disease-idiopathic & 96 \\
10 & Sensory symptoms-? cause (all categories) & 81 \\
11 & Cervical spondylosis (all categories) & 78 \\
12 & Transient ischaemic attacks & 75 \\
13 & Vertigo (all categories) & 73 \\
14 & Polyneuritis (all categories) & 70 \\
15 & Median nerve lesions (all types) & 59 \\
16 & Ulnar nerve lesions (all types) & 57 \\
17 & Non-organic symptoms (all types)* & 56 \\
18 & Lumbar spondylosis (all categories) & 44 \\
19 & Essential tremor & 44 \\
20 & Syncopal attacks (all types) & 43 \\
21 & Post-viral disorders (all types) & 39 \\
22 & Depression (all categories)* & 37 \\
& Total & 2284 \\
\hline & M & \\
\hline
\end{tabular}

*Only listed if the problem is significant.

"Diffuse Nervous System Disease" describes those conditions such as hydrocephalus, the encephalopathies, congenital abnormalities and other diffuse conditions like Alzheimer's disease, which cannot be easily classified elsewhere in the system.

Episodes of loss of consciousness and pain in the head and face account for a third of all diagnoses and these, plus movement disorders, cranial and peripheral nerve disease and vascular disease make up $60 \%$ of the total. The overall numbers rose by $27.5 \%$ from 1975 to 1986 , but the proportions in the majority of the categories have altered very little. Half the number of tumours were seen in the later years compared to 1975 and twice as many patients with cranial nerve disorders were seen in each of the later years, but in all other categories only minor differences are evident. In some, the percentage values have fallen (multiple sclerosis and vascular disease as examples), but the absolute numbers referred each year have remained very similar.

Leading individual diagnoses. The leading 22 diagnoses for the years 1984-1986 are listed in Table 3, these being conditions seen 36 or more times and, therefore, as an average, at least once a month. The majority of the diagnostic categories are easily recognised but some require explanation. The epilepsies are split into early and late onset either side of the age of 20 years, because data previously published by Merlis ${ }^{16}$ indicates that approximately $75 \%$ start before that age and $25 \%$ after, which makes for statistical convenience. The term "?Fit/?Faint" describes episodes of loss of consciousness which cannot be labelled otherwise because an eye witness account is not available or because the attacks have characteristics that make labelling difficult. The term "Sensory symptoms-? cause" covers a wide range of sensory problems for which no obvious cause can be found. "Nonorganic symptoms" defines a range of disorders where the character and distribution of the symptoms, plus the
Table 4 Incidence in population and in neurology clinic

\begin{tabular}{|c|c|c|c|}
\hline Diagnosis & $\begin{array}{l}\text { No seen } \\
3 \text { years } \\
\text { Gloucs. }\end{array}$ & $\begin{array}{l}\text { Expected } \\
\text { incidence } \\
3 \text { years }\end{array}$ & $\begin{array}{l}\text { No seen } \\
\text { as \% of } \\
\text { expected }\end{array}$ \\
\hline $\begin{array}{l}\text { Vascular spinal cord disease } \\
\text { Chronic myelopathy } \\
\text { Multiple sclerosis } \\
\text { Myasthenia gravis } \\
\text { Hereditary ataxias } \\
\text { Polymyositis } \\
\text { Motor neurone disease } \\
\text { Epilepsy late onset } \\
\text { Acute myelitis } \\
\text { Malignant primary cord tumour } \\
\text { Hereditary striopallidal disease } \\
\text { Guillain Barré } \\
\text { Parkinson's disease } \\
\text { Syringomyelia } \\
\text { Malignant primary cerebral tumour } \\
\text { Epilepsy early onset } \\
\text { Mononeuropathy } \\
\text { Trigeminal neuralgia } \\
\text { Transient ischaemic attacks } \\
\text { Neurological symptoms but no } \\
\text { disease } \\
\text { Cervical disc disease/pain } \\
\text { Polyneuropathy } \\
\text { Primary benign cerebral tumour } \\
\text { Meningitis/Encephalitis } \\
\text { Secondary cerebral tumour } \\
\text { Secondary cord tumour } \\
\text { Headache not migraine } \\
\text { Sleep disorders } \\
\text { Intracranial abscess } \\
\text { Benign cord tumours } \\
\text { Migraine } \\
\text { Stroke (not TIA) } \\
\text { Subarachnoid haemorrhage } \\
\text { Dementia } \\
\text { Bell's palsy } \\
\text { Head injury-various } \\
\text { Lumbosacral disc disease/pain }\end{array}$ & $\begin{array}{r}12 \\
34 \\
140(97) \\
11 \\
11 \\
8 \\
29 \\
248 \\
2 \\
1 \\
4 \\
12 \\
108 \\
2 \\
23 \\
224 \\
155 \\
14 \\
75 \\
164 \\
78 \\
70 \\
15 \\
20 \\
18 \\
6 \\
222 \\
15 \\
1 \\
1 \\
241 \\
124 \\
12 \\
28 \\
15 \\
147 \\
44\end{array}$ & $\begin{array}{c}1 \cdot 5 \\
7 \cdot 5 \\
45 \\
6 \\
6 \\
7 \cdot 5 \\
30 \\
263 \\
3 \\
1 \cdot 5 \\
7 \cdot 5 \\
30 \\
300 \\
6 \\
75 \\
787 \\
600 \\
60 \\
450\end{array}$ & $\begin{array}{l}800 \\
453 \\
311(216) \\
183 \\
183 \\
107 \\
97 \\
94 \\
67 \\
67 \\
53 \\
40 \\
36 \\
33 \\
31 \\
28 \\
26 \\
23 \\
17\end{array}$ \\
\hline Total & 2334 & & \\
\hline
\end{tabular}

See text for details of methods and for source of population data.

behaviour of the patient during examination, suggest that there is no underlying organic cause. It is freely acknowledged that the latter two categories may overlap and that in some patients there could well be an underlying organic cause that has not been identified. As can be predicted from the data given in Table 2, the various types of headache and blackout are common and, indeed, they occupy five of the top eight places. Almost 30 patients of this type are seen each month. The 3020 patients seen in 1984-1986 generated 3714 diagnoses, of which 3334 were for neurological conditions. The 22 conditions listed in the table represent $68.5 \%$ of all the neurological diagnoses made in this period.

Incidence rates in the population and in the neurology service. It is possible, by using the data published by Kurtzke, ${ }^{4}$ to calculate the incidence of many neurological disorders in the 512,200 population of Gloucestershire and, by examining their incidence in the neurology service, to calculate the percentage pick up rate of these disorders. The following example illustrates the technique used. Kurtzke quotes an approximate annual incidence rate for motor neuron disease of 2:100,000, which gives 30:500,000 (the approximate population of the county) for three years. In the 
period 1984-1986, 29 such patients were seen, which gives a $97 \%$ pick up rate.

Table 4 lists 37 conditions, in descending order of pick up rates to illustrate the use of this technique. A total of 2334 diagnoses are listed, which represents $70 \%$ of all the neurological diagnoses in this three year period.

Some explanatory comments are required concerning some of the headings. Vascular disease of the spinal cord includes both infarcts and intermittent cord and cauda equina ischaemia. Chronic myelopathy is a term used to define progressive myelopathies that are not obviously due to compression, spondylosis, demyelination or other detectable cause. The figures for multiple sclerosis are: definite + probable + possible $=140$ and definite + probable $=97$, using the McDonald and Halliday system. ${ }^{17}$ The values given illustrate that multiple sclerosis is far more prevalent in this part of the United Kingdom than has been suspected hitherto, an observation also made by Compston. ${ }^{18}$ Myasthenia gravis includes general and ocular myasthenia. The epilepsies are divided into early and late onset according to the method given earlier. The values listed under "Neurological symptoms but no disease" must be interpreted with caution, for here we cannot be sure that like is being compared with like. The value for the incidence of Bell's palsy is deceptive, for that disorder, more than any other, leads to many telephone conversations with family doctors and relatively few consultations. Finally, it should be noted that there are several headings where Kurtzke indicates that the proportion cited is that which he feels represents the number of patients who should be seen by a "physician competent in neurology" and these include headaches, cervical and lumbar disc disease and head injuries. Here we have to make allowances for the fact that the medical approach to these conditions is almost certainly different in the United States from that employed in this country.

\section{Discussion}

Neurology as a clinical speciality has grown slowly in the United Kingdom. In 1961 the Platt Report on Medical Staffing ${ }^{19}$ recommended that there be one neurologist for every 500,000 people. By 1971 there were 112 neurologists in the United Kingdom, which approximates to that recommendation. In 1986 there were 170 neurologists in England and Wales, ${ }^{20}$ which gives a ratio of approximately 1:277,000. It is clear that the distribution of consultants is uneven throughout the country, for in Gloucestershire the population per neurologist is nearly double the national value. In early 1988 the Association of British Neurologists adopted the policy that there should be one neurologist for 200,000 population. ${ }^{3}$ This must be regarded as an achievable but interim objective, because it is probable that the real need is for a different and probably smaller population per consultant. In order to calculate this real need, complex analyses are required and basic to any such analysis must be an understanding of how the system works now. This is part of the purpose of the present paper. The situation in Gloucestershire lends itself to this type of analysis, for there is one neurologist (with an interest in data collection!) in the centre of a clearly defined population approximately equidistant from all adjacent neurology services. It is unlikely that the data presented so far are absolutely representative of what happens in the county, for it is quite probable that some patients go elsewhere for their neurological advice, but it is probable that the picture that has emerged is comparable with what happens in other areas where the collection of reliable data may not be quite as straightforward.

In order to draw conclusions concerning the way these data may help in analysing what is needed in the future, it is necessary to discuss the implications of the data on referral patterns and then the widely variable pick up rates that were illustrated earlier.

\section{Referral patterns.}

In the United Kingdom the majority of patients seen by neurologists are referred by other doctors and a very small proportion come from other sources. In the present study, between 1984 and 1986, family doctors referred $72 \%$, consultants $24 \%$ and other agencies (solicitors etc.) $4 \%$. No patients referred themselves. These figures contrast with the situation for neurologists in the USA, where physicians refer $80 \%$, other agencies $7 \%$ and $13 \%$ are self referrals. ${ }^{6}$

With the exception of those neurologists with a special interest in certain disorders, the majority do not actively invite referrals of patients with particular types of illness; instead, they passively accept any patients that are sent to them. The case mix of patients described in Tables 2 to 4 illustrates the types of problems referred in Gloucestershire, where the passive approach is used.

There are various ways of inspecting whether this pattern of diagnoses is fixed or not. The evidence presented so far reveals a very similar pattern from year to year, even from decade to decade and this cannot be attributed to the same population of doctors doing the same thing year after year, because there was a turn over of at least a third of local family doctors and consultants in the decade under examination.

The total number of patients referred is rising steadily, for in $198627.5 \%$ more new patients were seen than in 1975. The overall pattern of diagnoses is very similar over this decade, so it appears that the general threshold for referral is dropping, but the disorder specific thresholds are not altering very much. The only real exceptions are for brain tumours and cranial nerve disorders. The $50 \%$ drop in the numbers with brain tumours probably reflects the fact that CT scanners were installed between 1975 and 1984-1986, so other doctors are now diagnosing these tumours and referring them directly for neurosurgical advice, whereas previously neurological help would have been 
requested. The reason for the rise in cranial nerve disorders is not quite so clear, although it is possible that in the later period the perceived need for an accurate diagnosis was greater and since the CT scan did not provide this, help from the neurologist was sought. (This is a guess).

As the referral rate is rising it can be asked how far will this rise go before the rate levels out. This question cannot be answered with clarity, although one highly relevant influence can be studied. There is no doubt that the length of the out-patient waiting list influences referral rates and a stark insight into this relationship is obtained by examining the effect of an exercise conducted in the summer of 1985 at the mid-point of the period under scrutiny. During the twelve months prior to July 1985 , when the maximum waiting time at the Gloucestershire Royal Hospital was stable at approximately 22 weeks, 487 referrals (new patients and old ones discharged more than a year earlier) were seen in the routine out-patients clinic. In the first week of July 198564 new patients were seen, which reduced the maximum waiting time to $10-11$ weeks. This new waiting time was published in the monthly digest of waiting list figures distributed to family doctors. In the next twelve months the waiting time rose steadily to 28 weeks, despite a total of 654 referrals being seen in that period. During this second twelve months, $34 \%$ more patients were seen and, if account is taken of those making up the waiting list, it is probable that at least $50 \%$ more were referred. This indicates that the previous lengthy waiting list had inhibited referrals and that the shorter list unleashed a flood of additional referrals. From this experience it has been deduced that there is a considerable demand for neurological services which is not being satisfied. What cannot be calculated is the absolute size of that demand. One further observation which is revealed by this exercise concerns the case mix of patients referred. In the two years 1984 and 1986, on either side of the blitz on the waiting list, the case mix is very similar, with no evidence of a different pattern of referral. In essence, there is no evidence that patients with selected and more serious disorders were referred when appointments were scarce and that a more liberal list of less serious disorders were referred when appointments were less scarce.

A further insight into the same phenomenon is obtained by studying patients sent for an opinion by high referring doctors. During 1984 there were 796 referrals of new patients from 288 different family doctors and of these, $92(11.5 \%)$ came from only 10 doctors $(3 \cdot 5 \%)$.

A comparison of the case mix of these 92 patients and the remaining 704 shows minimal differences. There is a modest increase in the proportion of patients with headaches in the high referral list, but that is the only category where a difference can be seen. It appears that those who refer a lot simply have a lower general threshold for referral than their colleagues.

Thus, with few exceptions, there is considerable stability of patterns of referral for specific conditions and this pattern is evident when comparisons are made from one decade to the next and when smaller or larger numbers of patients are seen. It is also evident whether appointments are scarce or not and when patients from high referring doctors are compared to those from doctors with lower referral rates. It is as if there is a natural law which determines that, given a wide variety of circumstances a neurologist is likely to see exactly the same mixture of patients every year.

\section{Pick up rates}

The analyses presented earlier illustrate that for some disorders a high proportion of those in the community are referred for a neurological opinion, whereas for other conditions only a modest proportion are referred. These analyses have been based upon the figures published by $\mathrm{Kurtzke}^{4}$ and it has to be acknowledged that for some conditions they are obviously inaccurate, particularly for those at the top of table 4 where the incidence in the neurology service exceeds the calculated incidence in the community. The difficulties involved in producing accurate and, therefore, useful incidence figures are considerable and are well illustrated by Sander and Shorvon ${ }^{21}$ in their review of incidence studies in epilepsy in which they quote a very wide range of values from different authors. It seems highly probable that this problem applies to all the disorders listed in table 4 , so the conclusions to be drawn from those data must be coloured by the possibility that inaccuracies, possibly substantial, may have been introduced. There seems to be no better methodology available at the moment, although accurate British figures would help in future analyses of this sort. Despite these obvious limitations, it is still possible to draw certain conclusions concerning the pick up rate of neurological diseases.

Bearing in mind the stability of the referral habits discussed above, it is clear that referring doctors perceive that some disorders require the opinion of a neurologist more than others. No doubts appear to exist concerning certain types of spinal cord disease, multiple sclerosis, myasthenia gravis and late onset epilepsy, for each of these has a similar incidence in the neurology service to that calculated for the community. Other conditions, which are obviously the legitimate business of a neurologist are referred in rather smaller proportions. Only a third of patients with Parkinson's disease are seen and it is quite likely that the family doctors treat the other two thirds themselves, although some may be seen by general 
physicians or geriatricians. In this context it is of interest that the majority of patients seen in the neurology service are those referred with treatment problems. The percentage of the calculated number of brain tumours that are seen suggests that many are diagnosed and referred for neurosurgical treatment by other doctors and that the perceived need for neurological advice is small. Various comments can be made concerning peripheral nerve disorders. It seems unlikely that many patients in the county suffer the Guillain Barré syndrome without the author hearing of them, so Kurtzke's figures on this disease do not apply. On the other hand, it is entirely possible that many patients with alcoholic, B12 deficiency or diabetic neuropathy are not referred, because they are legitimately dealt with by family doctors or other physicians. The same comments apply to the mononeuronpathies, for it is certain that many patients, particularly those with carpal tunnel syndrome or ulnar nerve lesions, are dealt with by orthopaedic surgeons and it is quite possible that some with the former condition are not referred at all. Another category worthy of note is cerebrovascular disease. The pick up rates for transient ischaemic attacks and established stroke are $17 \%$ and $6 \%$ respectively. As with the other disorders discussed already, these conditions are frequently managed by family doctors without outside help and if such help is needed, then it is commonly obtained from general physicians (particularly with acute stroke), geriatricians or others in the hospital service. Some of the conditions listed in table 4 , such as headache, dementia or head injury are common or very common, yet the percentage pick up rate is very small. Because headache is so very common in the community, such patients loom large in any clinic, but the number not referred is colossal by comparison. Clearly such patients are managed by others and it is highly likely that the majority are cared for by their family doctors without any additional help. Many other conditions are listed in Table 4 for which the same type of comments would apply.

The most reasonable conclusion to draw from these data is that family doctors manage the majority of the straightforward neurological diseases themselves and that they refer only a minority. This conclusion is supported by Wilkins and Smith ${ }^{22}$ who investigated the referral habits of 201 family doctors in the Manchester area. Within this cohort of doctors were 32 with high referral rates and they referred $12.3 \%$ of their patients with disorders of the nervous system and sense organs, whereas the 35 with low referral rates sent on only $3.6 \%$. Thus, between $87.7 \%$ and $96.4 \%$ of such patients were not referred for an opinion.

It is a common experience in British hospitals to find many in-patients with neurological disease under the care of specialists other than neurologists. Morrow and Patterson ${ }^{23}$ illustrated this when they observed that $19 \%$ of 925 adult medical admissions to a Northern Ireland District Hospital were suffering from neurological disorders. Of these 180 patients, only 15 were sent on for neurological or neurosurgical advice. The hospital in question did not have a neurologist and the authors do not comment on how many more patients they would have referred if there had been a neurologist on site. In Gloucestershire many patients with stroke are cared for by general physicians without neurological help being requested and likewise specialists in other disciplines care for many patients with headache, vertigo, head injury, visual problems and dementia without seeking advice. It is possible that some are not referred because it is realised that the author is already busy, so that he cannot see everything and it is even possible that previous experience has indicated that his opinion is not worth having anyway! However, it is far more likely that those caring for these patients believe that the conditions in question are just as legitimately their business as that of the neurologist.

\section{Implications for the speciality}

An important step in the process of deciding how many neurologists are needed in the United Kingdom, is the creation of a consensus view on how the speciality should be defined. Superficially this seems like a ridiculous suggestion, but there is a manifest gap between the day to day reality of what neurologists actually do and what they think they should be? doing. ${ }^{13-15}$ Neurology is not the speciality that deals exclusively with organic diseases of the nervous system, for many patients with no structural disease are seen. Likewise, it is not the only speciality that deals with organic nervous system disease, for others do too. At the present time what neurologists do and, therefore, what defines the speciality, is being decided by those who refer certain clinical problems but not others. The present study has revealed that referring doctors perceive some disorders to be appropriate for referral to a neurologist and others not. Examples have been given of those disorders where the views of the referring doctors and the neurologist match concerning the appropriateness of referral, but there are some conditions where a mismatch occurs. This comment does not refer to conditions that should have been sent elsewhere, but instead to the opposite, for many patients with cerebrovascular disease, nervous system infections and dementia are not sent for a neurological opinion. The question can be asked, therefore: Are all these things really the business of a neurologist? If it is decided that they are, then ideally all should be referred for neurological advice and this decision will then have implications concerning the numbers of neurologists that are required. If they are 
not, then that decision too will have implications concerning manpower. As has been seen from the data presented earlier, the majority of such patients in Gloucestershire do not see a neurologist.

Relevant to the above are the comments reported by Hopkins $^{2}$ when he discussed possible types of neurologists. He gave the views of professors of medicine and neurologists and it is clear that these two groups have starkly different views on the topic of who should deal with neurological illnesses. If anything, the views of the professors are the more pragmatic, for they acknowledge the status quo and recognise that much neurology is indeed dealt with by non-neurologists, whereas the views of the neurologists are less so, for they appear to believe that only neurologists should do neurology. The reality is that much neurology is done by non-neurologists and this happens because family doctors deal with some of it themselves and, when referring patients on for additional advice, they do not always refer to a neurologist. If there are too few neurologists and they all have long waiting lists, then this is reasonable, but it does not necessarily follow that if neurological services were freely available, they would then send all patients to the neurologists. They may have concluded that neurologists do neither better nor worse than other specialists in managing certain conditions and that targeted referral is unnecessary.

A number of practical questions have emerged from the present study and these could be answered by comparable studies done in other areas. It would be useful to know if the case mix of patients seen by other - neurologists is the same as it is in Gloucestershire. If it is, then the reasons for this pattern should be explored more deeply than has been possible in the present study. If it is not, then the reasons for the differences should be examined, for these reasons might facilitate an understanding of the referral process. Attempts should also be made to examine whether referral habits can be altered, for if they can then efforts could be made in the future to attract more appropriate referrals to the speciality. The evidence from the present study on this topic is meagre, for the only factor that has apparently changed the referral pattern is the CT scanner. There is no evidence that lectures on neurological subjects or detailed clinic letters have had any real impact on referral practices. Other techniques may work and they should be examined. By far the most interesting and relevant set of questions are those which relate to the overall workload in areas where there are more neurologists. In such areas, do waiting lists disappear? Do such neurologists see more or less organic disease? Do they see a greater proportion of stroke and dementia or do they simply see more headaches? Knowing the answers to these questions will move us nearer to an understanding of how many neurologists are needed in a given population.

At the present time the need for more neurologists in the United Kingdom is fairly clear, but how many do we need? In the USA there will be one neurologist for every 34,800 people in 1990 which is about ten times the UK national average. ${ }^{24}$ It seems probable that this proportion is too high ${ }^{1}$ and that we need fewer than that, even though there are some in the USA who believe that these numbers are about right and may even be too low. ${ }^{24}$ An understanding of epidemiological factors, referral habits (and their reasons) and the general dynamics of the service as it exists now may permit a better perception of what neurologists do now and what they could or should do in the future which, in turn, will give a better idea of how many neurologists we really need. In this way we may avoid the apparent extravagances of the American system and at the same time escape from the present system, wherein neurologists are too few in number, the service is less than ideal and plans for the future are being based on guesses rather than on facts.

The painstaking and meticulous work of Mrs Marion Rumsey and Mrs Diane Rotherham, who entered the data into the computerised diagnostic index, is gratefully acknowledged.

\section{References}

1 Marsden CD. Editorial: what should neurologists do? J Neurol, Neurosurg, Psychiatry 1981;44:1059-60.

2 Hopkins A. Different types of neurologist. Br Med J 1984;288:1733-6.

3 Neurology in 1988 and beyond: a statement by the Association of British Neurologists 1988.

4 Kurtzke JF. The current neurologic burden of illness and injury in the United States. Neurology 1982;32:1207-14.

5 Brewis M, Poskanzer D, Rolland C, Miller H. Neurological disorders in an English City. Acta Neurol Scand 1966 42/S-24: 1-89.

6 Mendenhall RC. Medical Practice in the United States 1981; The Robert Wood Foundation.

7 Brust JCM. Neurology in a municipal teaching hospital. Sem Neurol 1985;5:32-5.

8 Horwich MS. General neurologic practice in an academic teaching institution. Sem Neurol 185;5:36-8.

9 Kelts KA, Ange D. The scope of neurologic practice in a rural setting. Sem Neurol 1985;5:39-45.

10 Mosher CG, Rozance JE. The practice of neurology in an HMO setting. Sem Neurol 1985;5:50-56.

11 Franklin GM, Ringel SP, Nelson LM, DeLapp C. Neurology practice patterns in Colorado. Neurology 1987;37:287-9.

12 Perkin GD. Necessity for inpatient services in neurological practice. J R Soc Med 1983;76:920-3.

13 Report of the working group on services for people with epilepsy. London: HMSO, 1986.

14 Physical disability in 1986 and beyond. A report of the Royal College of Physicians. J R Col Phys 1986;20:160-94.

15 Wade DT, Hewer RL. Epidemiology of some neurological diseases with special references to work load on the NHS. Int Rehab Med 1987;8:129-37.

16 Merlis JK. Epilepsy of late onset. In: Vinken PJ, Bruyn GW, eds. Handbook of Clinical Neurology Vol 15 1974. North Holland. 
17 McDonald WI, Halliday AM.Diagnosis and classification of multiple sclerosis. Br Med Bull 1977;33:4-8.

18 Swingler RJ, Compston DAS. The prevalence of multiple sclerosis in South East Wales. J Neurol Neurosurg Psychiatry 1988;51:1520-4.

19 Report of the joint working party on medical staffing structure in the hospital service. 1977. London: Her Majesty's Stationery Office.

20 Medical and dental staffing prospects in the NHS in England and Wales. DHSS. Health Trends 1986;18:49-56.

21 Sander JWA, Shorvon SD. Incidence and prevalence studies in epilepsy and their methodological problems: a review. J Neurol,
Neurosurg, Psychiatry 1987;50:829-39.

22 Wilkin D, Smith AG. Variation in general practitioners' referra rates to consultants. $J \boldsymbol{R}$ Coll Gen Pract 1987;37:360-3.

23 Morrow JI, Patterson VH. The neurological practice of a district general hospital. J Neurol Neurosurg Psychiatry 1987;50: 1397-1401.

24 Kurtzke JF, Bennett DR, Beringer GB, Goldsten M, Vates TS. Neurologists in the United States-past, present and future. Neurology 1986;36:1576-82.

25 Dyken ML. The continuing undersupply of neurologists in the 1980s: impressions based on data from three studies. Neurology 1982;32:651-6.

\section{Scrotal reflex}

"If, in children whose scrotum is relaxed, we press the finger upon the inner surface of the thigh, the testicle of the same side is drawn up, in consequence of a reflex action."

Romberg, MH. A Manual of the Nervous Diseases of Man, edited and translated by H Sieveking. London: The Sydenham Society, 1853.

RT ROSS

\section{Aphasia}

"It is quite necessary to distinguish two different phenomena in the act of speech, namely, the power of creating words as signs of our ideas and that of articulating these same words. There is, so to speak, an internal speech and an external speech; the latter is only the expression of the former."

Bouillaud, JB. Recherches cliniques propres a demontrer que la perte de la parole correspond a la lesion des lobules anterieurs de cerveau. Arch Gen Med 1825;8:25.

\section{Poliomyelitis}

"In the year 709 the ANNALS OF ULSTER record: "Pestis Quae Dicitur and Baccach, Cum Uentris Profluuiis, in Hibernia". MacArthur' discusses the possible identification of Baccach, which he translates as "lameness" in the sense of "weakness or disablement of any limb upper as well as lower". He says "the problem is to name an epidemic disease which might have given rise to numerous cases of paralysis or weakness of limbs ... I venture to suggest that the Baccach of 709 may have been poliomyelitis, popularly called "infantile paralysis", although it is far from being restricted to children. ... The initial phase of the infection would have passed the understanding of any monk of old, but no one could have failed to observe the trail of cripples left behind."

\section{References}

1 MacArthur, Sir William Porter. The identification of some pestilences recorded in the Irish Annals. Irish Historical Studies 1949;VI,169-88.

2 Bonser, William. The Medical Background of Anglo-Saxon England. London: The Welcome Historical Medical Library, $1963,83$.

RT ROSS

\section{The myopathies or muscular dystrophies}

"It has been shown that the distal type is a true myopathy and distinct from the disease described by Charcot, Marie, and Tooth (peroneal type), which is a myelopathic affection and should not be included under the myopathies."

Batten, Frederick E. $Q J$ Med 1909-10;3:313-27. 